\title{
Subjective Wellbeing and the Discount Rate
}

\author{
James Kennedy ${ }^{1}$ (i) \\ Published online: 14 March 2019 \\ (C) The Author(s) 2019
}

\begin{abstract}
Academic and policy interest in the determinants of subjective well-being continues to grow. To date, the role of temporal discounting - the extent to which people devalue future rewards-in people's reports of their subjective well-being has remained unexplored. This paper is the first to provide evidence on the relationship between discount rates and evaluative and hedonic subjective well-being. Using data from a nationally representative sample of 2000 UK respondents in multiple regression analyses, the results suggest that people who devalue future rewards are less satisfied with life and less happy than those who place greater value on future outcomes. However, those who discount heavily are also more likely to expect that they will be happier in the future.
\end{abstract}

Keywords Subjective well-being $\cdot$ Life satisfaction $\cdot$ Happiness $\cdot$ Discount rate

\section{Introduction}

This paper explores a potential relationship between the discount rate of individuals and their subjective wellbeing. This is an important area for study for several reasons. Policymakers across the world are increasingly adopting subjective wellbeing as a tool to measure individual welfare and societal progress, using this construct as a metric against which to evaluate the efficacy of their policies (Stiglitz et al. 2009; Dolan and White 2007). In efforts to improve levels of quality of life, researchers and policists are eager to identify as many of determinants of subjective wellbeing as possible, with a particular emphasis on those than can be practically measured. This study is the first attempt to test whether individual discount rates are one such determinant of subjective well-being.

The discount rate has already been shown to predict performance in domains critical to human wellbeing-namely health and financial behaviours (Dolan et al. 2008). Not only is it a predictor in these vital domains, it predicts these variables to a powerful extent (Chabris et al. 2008). This predictive power seems unlikely to be isolated to only these two domains. This study is designed to contribute a more complete picture of its effects.

Electronic supplementary material The online version of this article (https://doi.org/10.1007/s1090 2-019-00096-9) contains supplementary material, which is available to authorized users.

James Kennedy

james5.kennedy@live.uwe.ac.uk

1 Faculty of Business and Law, University of the West of England (UWE), Bristol, England, UK 
Any effect of the discount rate on wellbeing, especially once combined with those on health and wealth, would suggest that there is a crucial underlying mechanism at work. Researchers have posited that this may be down to our detection systems (de Wit et al. 2007; Dohmen et al. 2007). This refers to our ability to accurately perceive and analyse the nature of rewards in the future. Detection systems can be trained, suggesting that there is room for the refinement and potentially alteration of these systems. This refinement would make for more efficient decision making at both the societal and personal level which may in turn result in enhanced wellbeing.

This study contributes to the literature on both wellbeing and the discount rate in 3 ways. Firstly, it examines a potential link between lower discount rates and higher life satisfaction. Secondly, it compares this link with that between the discount rate and momentary happiness. Finally, it contrasts these results with the relationship between the discount rate and expected future life satisfaction.

\subsection{Wellbeing}

The potential benefits of achieving a better understanding of wellbeing, be it "life satisfaction", "happiness" or otherwise, requires little justification. The disciplines of economics, social science and psychology are groaning under the weight of new evidence in the area. From Aristotle to Bentham, humanity has long desired the means to measure and increase societal wellbeing and now that this area of research is well established, a growing number of factors have been found to hold strong relationships with this vital variable.

Some of the most basic constituents of our identity, including our gender and age, have been shown to have a significant impact on our wellbeing, in addition to elements developed over a long period of time such as our education (Dolan et al. 2008). Our income, both in its gross form (within limits-Boyce and Wood 2010) and relative to those around us (Brewer et al. 2006) appears to have an effect, while our health (in all of its forms) and the quality of our sleep have also been shown to be significant contributors (Ferrer-iCarbonell and Gowdy 2005). Employment factors such as our working status (Meier and Stutzer 2007) and the quality of our commute make significant contributions while our personality itself appears to predispose us to greater and lesser levels of wellbeing (Grant et al. 2009). Overall, the list of contributing factors is diverse, but this diversity makes further research no less important, as the increase of societal wellbeing is one of, if not the, primary purpose of governance and overall societal wellbeing is the accumulation of individual factors acting on individual people.

Layard (2011) claims that measures of wellbeing can be broadly separated into three types-evaluative, experiential and eudaimonic. Evaluative measures represent a person's analysis of his/her life as a whole, whereas experiential wellbeing focuses more on happiness 'in the moment'. The former is judged to be the most important for societies to measure, track and attempt to increase, however, the second is also recognised as being extremely important. The practical challenges of assessing a person's eudaimonic happiness (the happiness of meaning and self-actualisation in life) led to a focus within this study the first two of these aspects. The third variable utilised in the study is 'expected future wellbeing'. This addition is for two main reasons. Firstly, despite life satisfaction being relatively stable over time, people perceive some degree of change as being likely (Röcke and Lachman 2008). This perception of change may predict other outcomes vital to wellbeing (Lang et al. 2013). Secondly, this variable introduces a useful element of temporality to a cross-sectional study. 


\subsection{Wellbeing and the Discount Rate}

The discount rate refers to the tendency of people to give greater weight to payoffs in the present than those in the future. The individual differences in this tendency are sizeable and well documented (O'Donoghue and Rabin 1999). Though there has been study of the role of the discount rate as a determinant of behaviour in recent years, research that frames it as an aspect of personality is in a relatively nascent stage. The section below contains a summary of this research to date and the rationale for the hypothesis that it has a level of determinative power that is greater than has been demonstrated thus far.

As with any potential new determinant of behaviour it is important to establish the distinctiveness of the discount rate from factors previously established to have a significant relationship with wellbeing. A principal area of overlap might be with personality traits, however the results of Manning et al.'s (2014) study into the relationships between the "Big 5" personality traits and the discount rate found that since it does not vary along the continuum of any of the individual factors. Temporal discounting sits largely outside this 5 factor framework.

Gubler and Pierce (2014) describe temporal discounting as being an underlying trait that is durable, domain-interdependent and one that predicts behaviours in many different dimensions. Odum (2011) supports this finding, asserting that there are at least three areas of evidence that support the idea of temporal discounting as a distinct trait. Firstly, it changes as a person matures as part of normal developmental and experiential adaption, secondly, it is correlated across different domains of decision making. Finally it appears to be highly heritable.

Previous research has not investigated a possible link between the discount rate and subjective wellbeing, though the list of human circumstances, conditions and characteristics shown to have a significant relationship with the discount rate is growing. Thus far, a low discount rate has been shown to positively predict income (Green et al. 1996), education levels (Warner and Pleeter 2001), working memory (Bickel et al. 2011), detection systems (de Wit et al. 2007; Dohmen et al. 2007), accurate perception of benefit trade-offs of cash (Funder and Block 1989) and the consumption of candy bars (Mischel and Metzner 1962), a sensation of power and control (Joshi and Fast 2013), IQ across a wide range of conditions (Shamosh and Gray 2007) and an absence of procrastination (Reuben et al. 2007). The sum of these findings imply that a low discount rate appears to be a predictor of positive human behaviour - and would alone be enough to warrant investigation into a more direct relationship between the discount rate and overall wellbeing levels. However, it is worth briefly exploring two further areas, both crucial to wellbeing, which have benefited from more detailed research in the area. These are savings and health.

One of the more complete studies into the relationship between discount rate and financial decision-making was by Chapman and Elstein (1995), who found that a steeper discount rate predicts poorer savings behaviours. The positive reverse has also been shown to be true. Ersner-Hershfield et al. (2009) found that those with a relatively shallow discount rate were significantly more likely to engage in a wide array of financial saving behaviours. The extent of this effect is impressive. Chabris et al. (2008) found that our personal discount rate has at least as great an impact on our financial saving habits as the major demographic factors such as age, gender and education.

The other main area of personal discount rate research is health. In the same study that examined finance, Chapman and Elstein (1995) found our time preferences also relate to the temporal value attributed to our general health. Much of this research appears to focus 
on the negative health-related behaviours found to be more common amongst high discounters. Harrison et al. (2010) have found an association between the discount rate and both smoking behaviours and drug use. In a similar vein to financial behaviours, the study by Chabris et al. (2008) also found that our personal discount rate has at least as strong a level of predictive power over our smoking habits and BMI as demographic factors. When the authors combined several key health metrics into one index score they found personal discount rate to explain a quarter of its variation, while no demographic variable studied was able to explain more than a tenth. Story et al. (2014) conclude that steep discount rates predict smoking, drinking, drug use, obesity, risky sexual practice and several other health risk behaviours. High discount rates were also found to negatively predict proactive behaviours like exercise and other forms of preventative healthcare. Boyle et al. (2013) even found these rates to be a predictor of overall mortality.

The link between the findings on personal finance and health and my prediction that the discount rate will also have an effect on subjective wellbeing is based on three broad premises. Firstly, in relation to both finance and health, this potential relationship is likely because of the increase in positive behaviours in shallow discounters and the presence of deleterious ones (DellaVigna and Malmendier 2006) in those with a high discount rate. It seems unlikely that these two forces are only in action in the arenas of health and wealth, which leads me to suspect a more general relationship between the discount rate and overall wellbeing. The second deduction is drawn from previous research on decision-making (e.g. Bickel et al. 2011; de Wit et al. 2007; Dohmen et al. 2007) implying that those with lower discount rates make more adaptive decisions in the specific areas studied. It therefore seems likely that this spans other major areas of our lives as well, the most significant of which, arguably, is that of wellbeing. The third premise is derived from research into health and wealth, which concludes that the discount rate has a significant impact in areas relevant to life satisfaction and its constituent parts. As a consequence, this effect will be less subject to the influence of poorer material conditions, the insecurities that result from a poorer financial situation and poorer health, not to mention the cumulative regret relating to decisions (currently perhaps seen as maladaptive) of past decisions (Easterlin and Angelescu 2012). Much like with financial decisions, the proposed association between decisions relating to health and wellbeing here is intuitive. Good health behaviours often involve the foregoing of an immediate gratification (eating a bag of warm donuts every day) in the interest of a longer-term benefit (not becoming overweight). The relationships between all of these variables are likely to be intermingled, making the importance of finance and health behaviours in any regression analysis of the discount rate essential. It is difficult to overstate the importance of research to further understanding of human wellbeing. The search for effective predictors is now firmly lodged in the mainstream of scientific research, but to date studies have not focussed on its potential relationship with the discount rate. As this rate has been shown to have a strong relationship with many of wellbeing's constituent parts, this leaves what I believe to be a gap in the literature.

Another argument in favour of a detailed consideration of temporal discounting as a predictor of wellbeing is the sense that future events themselves have an extra benefit compared to those engaged in today, because the experience of anticipation acts as an additional enhancement. In simple terms, this means that when comparing an immediate reward to a future one, even if they were of the same value, one would be able to derive more enjoyment from the future one, as one would have the equal sized event itself, but with the addition of that time of anticipated enjoyment. This is an argument supported by literature in both economics and psychology (Loewenstein 1987; Gard et al. 2006). Thus, in the context of this paper, it follows that those with a lower discount rate would find 
themselves deferring rewards on a more regular basis than those with a high rate and would perceive themselves to be actively accumulating greater rewards over time, possibly resulting in higher overall life satisfaction.

On the basis of this literature review I hypothesise that each of evaluative, hedonic and predicted wellbeing are predicted by the discount rate.

\section{Method}

\subsection{Data}

Data for this study come from a nationally representative online survey of 2000 respondents, conducted in the UK in July 2016 by a public opinion agency Opinium Ltd, based in London, UK. The method of online data collection allowed for strict control of the sample size and composition, cost-effective data collection of a large sample and, importantly, variation of the ordering of questions to combat respondent fatigue.

Respondents were recruited from the company's established research panel and selected based on the specific socio-demographic demographic characteristics (age, gender, region, social grade, political votership and newspaper readership) to represent the UK-wide population. Each respondent was rewarded 50p for their participation in the study as part of an ongoing membership of the panel. ${ }^{1}$ Upon signing up to the panel the respondents give consent for their data for academic purposes. All responses are anonymous and it is not possible to identify individuals based on the available information. The software that conducts the survey automatically removes respondents who display rote responding, such as implausibly rapid response or 'straight-lining', where the same order of response is selected over a span of questions. This data cleaning was conducted prior to the establishment of the target 2000 person sample.

The survey was conducted solely for the purpose of this research study.

\subsection{Variables}

\subsubsection{Outcome Variables: Subjective Well-Being}

Three different well-being variables were used in the study: evaluative, hedonic and expected. Evaluative wellbeing was measured using the following question: "Taking all things together, how satisfied are you with your life?", with possible answers ranging from 1 (not satisfied at all) to 10 (fully satisfied) - a standard way to capture evaluative wellbeing used, e.g., by OECD (2013) and the World Values Survey (2005).

Life satisfaction was distributed around scores of 7 and 8 out of 10 (43\% of people rate themselves as one of these two scores). The mean score was 6.8. The shape of the life satisfaction score distribution, shown in Fig. 1, conforms with existing well-being research (Helliwell et al. 2016).

\footnotetext{
1 Respondents can redeem rewards once they reach a level of $£ 50$ from participation in this and other studies. This method is used to motivate respondents to complete surveys by making them feel that they are being rewarded for their time, without being a great enough reward that they would only conduct the study for financial purposes.
} 


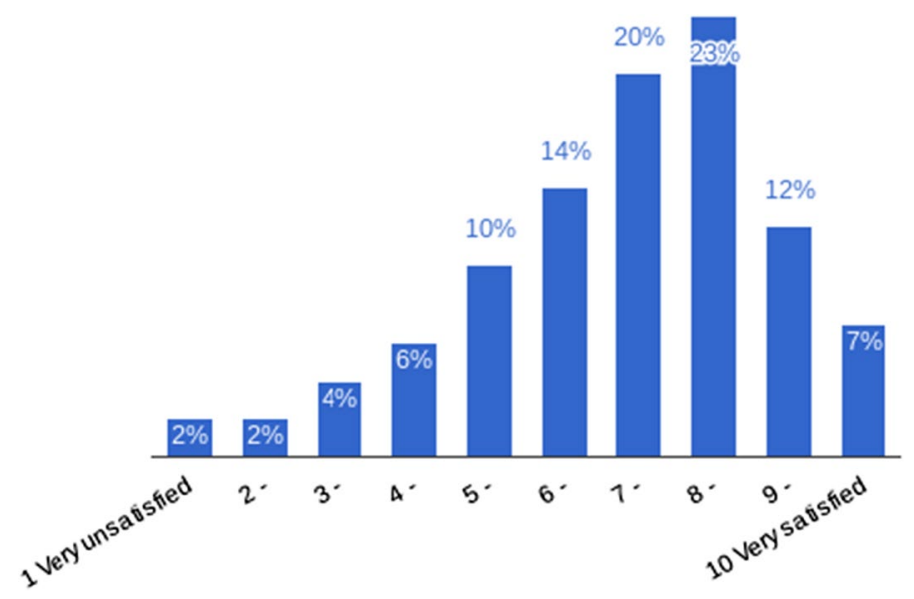

Fig. 1 Distribution of life satisfaction

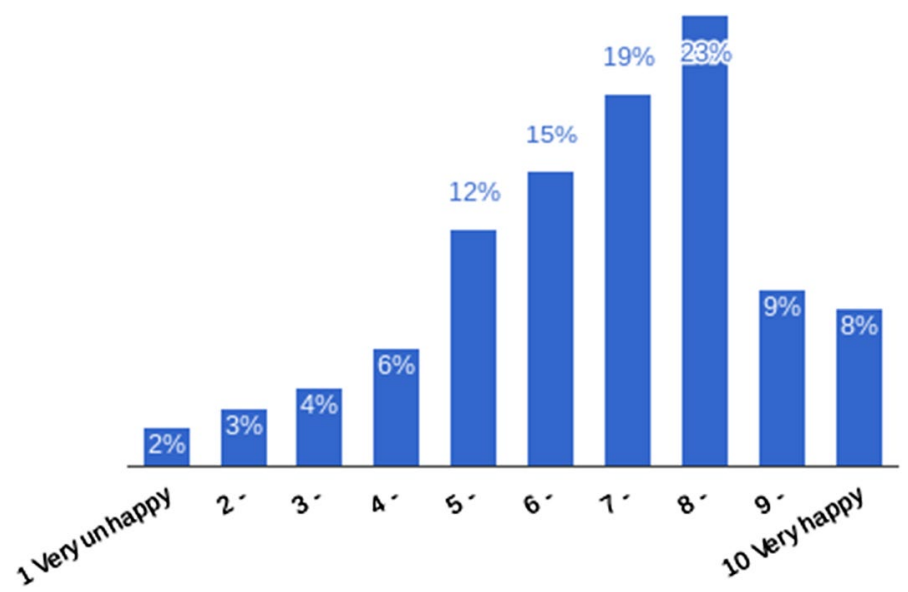

Fig. 2 Distribution of hedonic wellbeing

Hedonic well-being was measured using the question "How happy do you feel right at this moment?", with possible answers ranging from 1 (Very unhappy) to 10 (Very happy). The wording of the question was designed to measure an immediate, sensation of happiness. The distribution of answers, shown in Fig. 2, follows a shape similar to that of overall life satisfaction: scores 7 and 8 were the most frequent answers, and the mean was 6.7 (not statistically different from the mean of life satisfaction). The correlation between the evaluative and hedonic well-being variables is 0.76 .

Predicted well-being was captured using a question "Do you expect to be happier or less happy in 2 years time?", with possible answers ranging from 0 (much less happy) to 10 (much happier). Because of the temporal nature of the question one would expect respondents to answer it in an evaluative way, since it requires conscious projection of oneself into the future.

The mean score is 6.1 , and $46 \%$ of respondents selected score 5-implying that they expect to be as happy in 2 years as they are now. Slightly more people were optimistic 


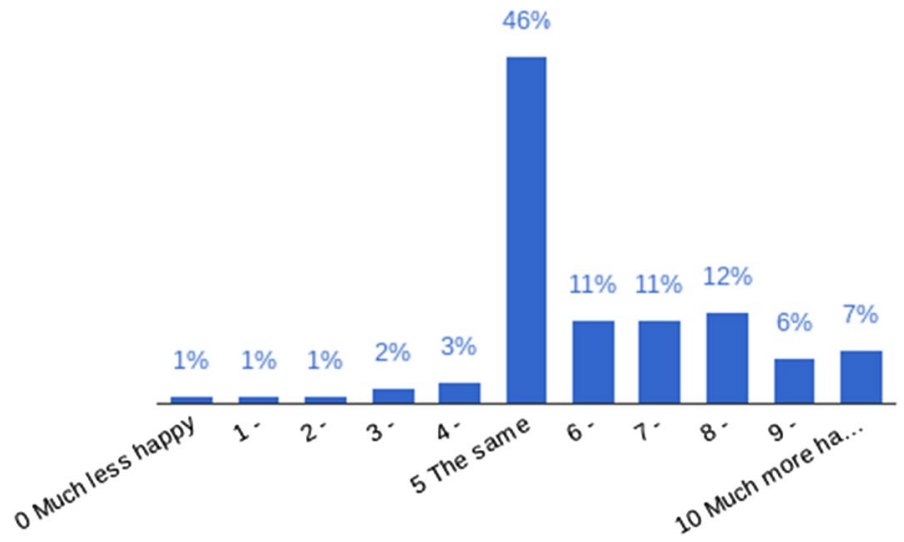

Fig. 3 Distribution of expected future life satisfaction (2 years)

about their future with $47 \%$ of respondents believing they will be happier in 2 years time than now. This is consistent with the findings from previous research in the area (Frijters et al. 2009). This variable is significantly correlated with both evaluative and hedonic wellbeing, although the correlation coefficients are relatively low ( 0.24 and 0.2 , respectively). The distribution of these results can be seen in Fig. 3.

\subsubsection{Independent Variable: Discount Rate}

The primary measurement of the discount rate was derived from the question: "Imagine you were awarded a prize $[£ 10,000$ or $£ 100,000]$ that you will received in [6 weeks, 9 months or three and a half years]. What is the maximum amount of that prize that you would be willing to give up to receive the reward today?" The size of the prize and timing were varied to reflect the changing nature of the discount rate with reward magnitude and time. The questions with various prize size-time trade-offs were asked in a random order.

Figures 4 and 5 show the mean temporal discounts of the 2000 respondents over time using the two different prize value bases, $£ 10,000$ and $£ 100,000$. In both cases, people discount more heavily in the short term, before the rate flattens out over the longer term. This shape is compatible with the prevailing literature in the area that points towards hyperbolic discounting (Odum 2011) though because of the relatively few data points this result does not rule out exponential discounting.

For each individual, six discount rates were obtained (based on two prize sizes and three time periods) and an average discount rate was calculated. The resultant variable is a positive percentage, the increasing size of which reflects greater devaluation of future rewards. The variable has a range of $0-4.65$, with a mean score of 0.034 and standard deviation of 0.044 .

In addition, a non-financial discount rate variable was included in the study, based on the question: "Imagine your employer has offered you an extra 10 days of paid holiday leave this year. How many extra days holiday would you need your employer to give you to wait until next year to have those extra days?" The mean response was 5.4, the mode was 4 and the standard deviation 4.5. This variable was included to provide a measure that did not depend on an individual's financial circumstances. 


\section{Discount over time of $£ 10,000$}

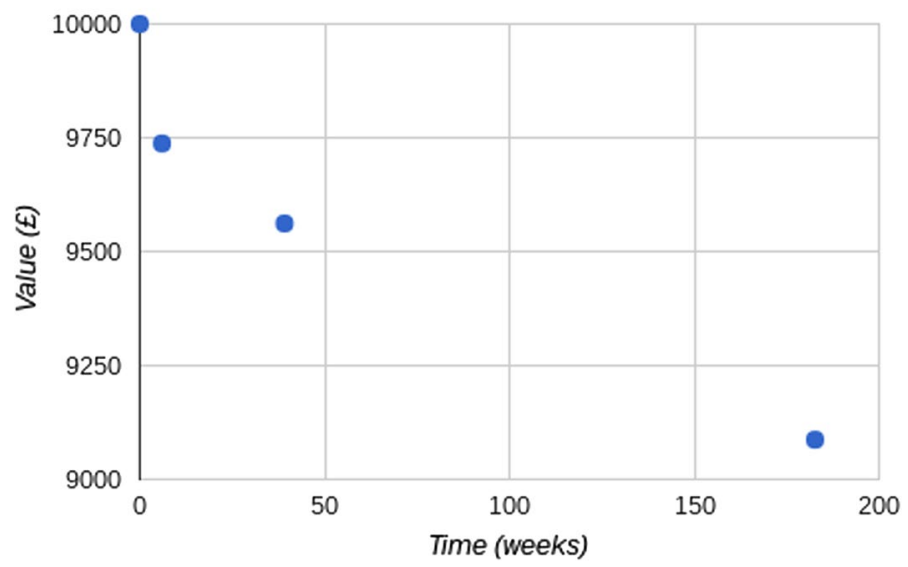

Fig. 4 Temporal discounting over time of a £10,000 reward

\section{Discount over time of $£ 100,000$}

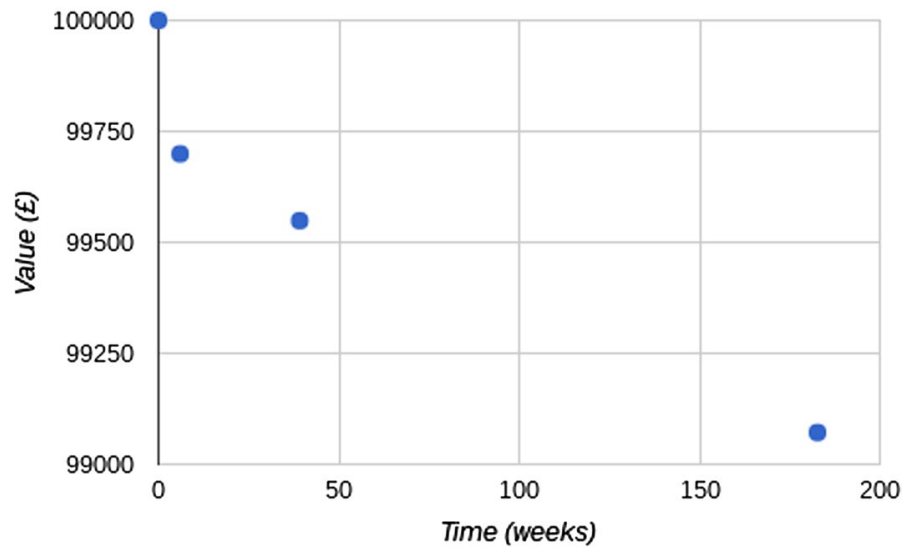

Fig. 5 Temporal discounting over time of a $£ 100,000$ reward

\subsubsection{Control Variables}

Demographic factors and other control variables were recorded to ensure the quality of any findings and to balance the statistical analyses. Because of the nature of wellbeing research most of these control variables constituted both sensible demographic controls and also variables that have been shown to have an impact on wellbeing. These included gender, age, region and education level, which cover much of the demographic contribution to wellbeing demonstrated in the literature (Dolan et al. 2008). Broader variables were also included which have been shown to have a significant contribution in the area of wellbeing, as follows. 
Both health and financial factors not only predict wellbeing themselves (Dolan et al. 2008) but have also been shown to be significantly predicted by the discount rate in the past (Chapman and Elstein 1995). As such, their potential as intervening variables should be considered. Through their inclusion in this study any significant relationship will be in spite of these intervening effects, since this type of decision-making and the differences in circumstance that they product appear likely to be inexorably linked to the way people make discount rate decisions. Also, because the main discount rate variable used was financial in its basis, it was important to include income in the analysis so as to ensure any predictive power of the discount rate that might be demonstrated does not merely reflect a lack of means (for example, accepting the smaller reward today due to present day financial constraints, thus making it the more immediately necessary option). Employment status (Meier and Stutzer 2007), sleep (Ferrer-i-Carbonell and Gowdy 2005) and the quality of a person's commute (Stutzer and Frey 2010) have also been shown to be consistent, powerful predictors of wellbeing and are available for analysis so were included in the final model. Finally, the "Big 5" personality traits were also included, in order to account for the contribution of established personality traits both to the respondents' wellbeing (Grant et al. 2009) and also their discount rates (Manning et al. 2014). By including these personality variables, it was also easier to consider the potential of the discount rate as an additional trait. The exact wording of the questions that created these variables is available in "Appendix 3, ESM".

2.2.3.1 Correlations Between Experimental Variables The negative correlation of the discount rate with conscientiousness and the positive correlation with neuroticism (see Table 1) are consistent with the findings of Manning et al. (2014) mentioned earlier in this paper. These results also suggest a separateness of the discount rate to any particular personality trait currently established. It is significantly negatively correlated with evaluative wellbeing but not with hedonic wellbeing and is significantly positively correlated with expected wellbeing. This suggests that the hypothesis that it is negatively predictive of evaluative wellbeing may be born out in the regression analyses. The discount rate is modestly negatively correlated with lower health, as expected $(-0.06)$ and is not significantly correlated with income, suggesting any issues of multicollinearity with the dependent variables are likely to be limited.

The correlation between the discount rate and age shown in Table 1 may be misleading since the relationship is nonlinear. The relationship is strongest in the youngest age group, followed by those in their $30 \mathrm{~s}$ and before troughing in the $40 \mathrm{~s}$ and $50 \mathrm{~s}$, then rising again in the $60 \mathrm{~s}$ and $70 \mathrm{~s}$. As a result, age-squared is included in the analysis as well as a simple age variable to account for its seemingly non-linear relationship with the discount rate. These results can be seen in Fig. 6 .

The shape shown here is corroborated by the results of the alternative discount rate variable: the holiday discount rate. This figure can be found "Appendix 4, ESM".

Finally, in a robustness check of the variables used UK region dummy variables were included but were found to be significant, while their inclusion did not affect any other results or the significance of any of the overall models. As a result, these dummy variables were not included in the final analyses in the next section. 


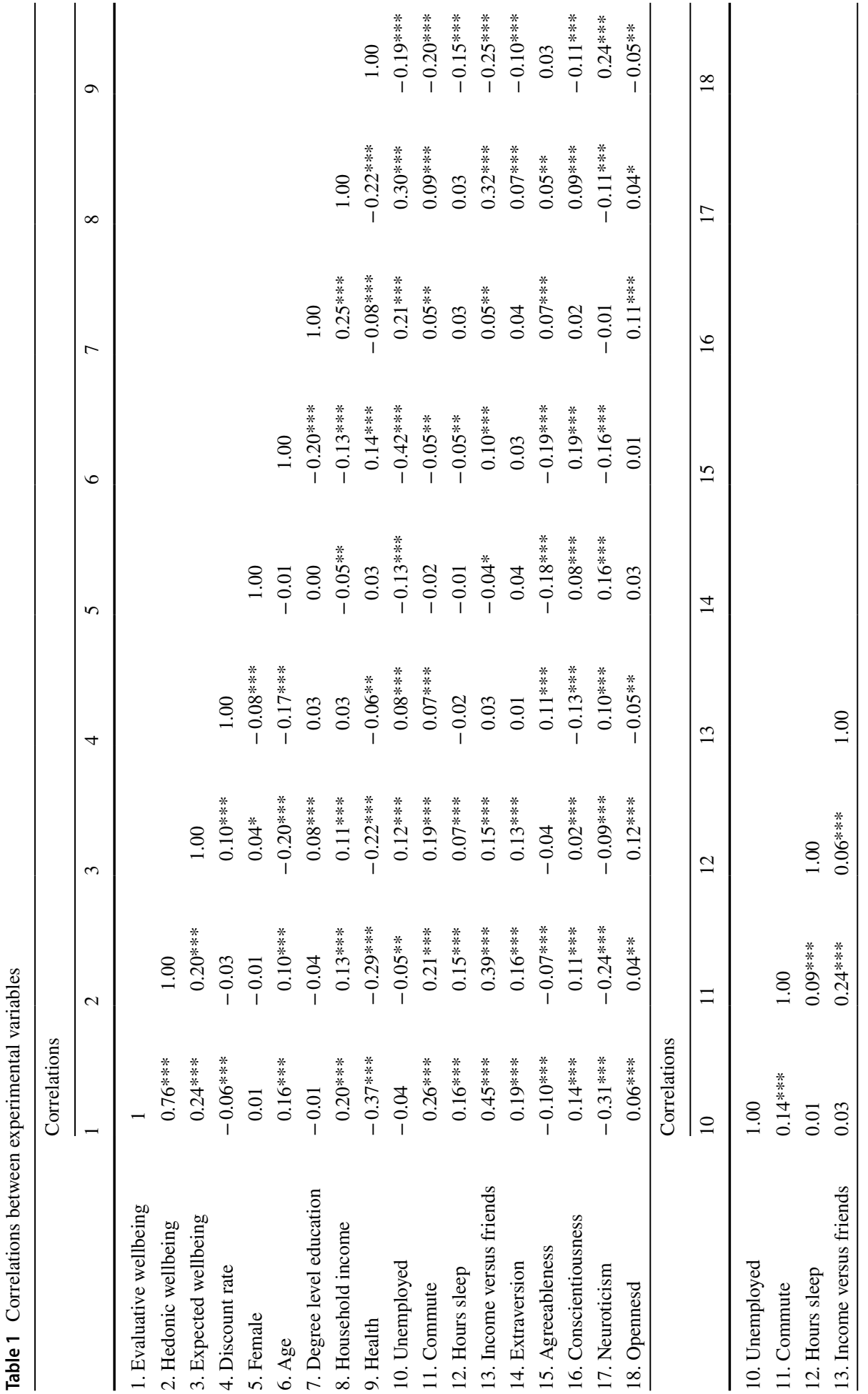




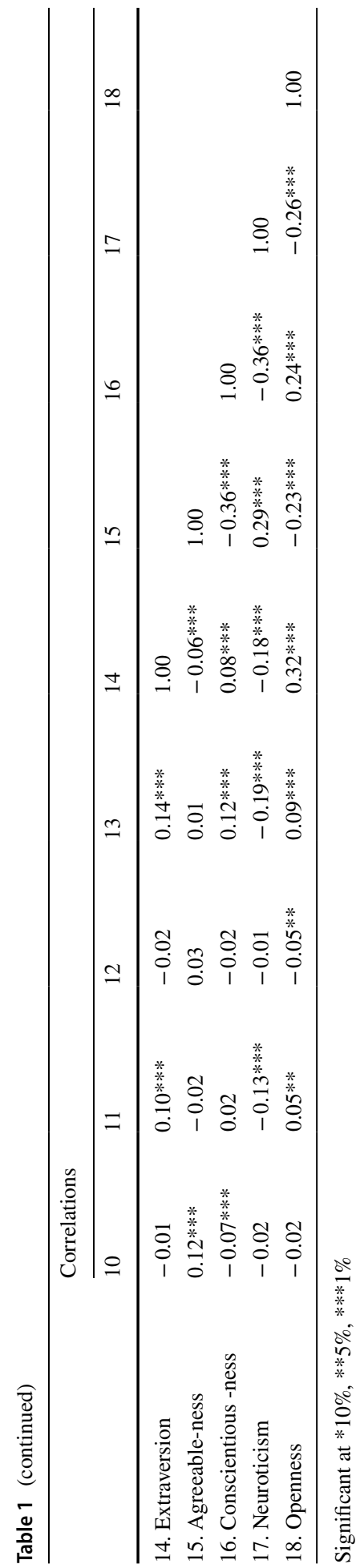




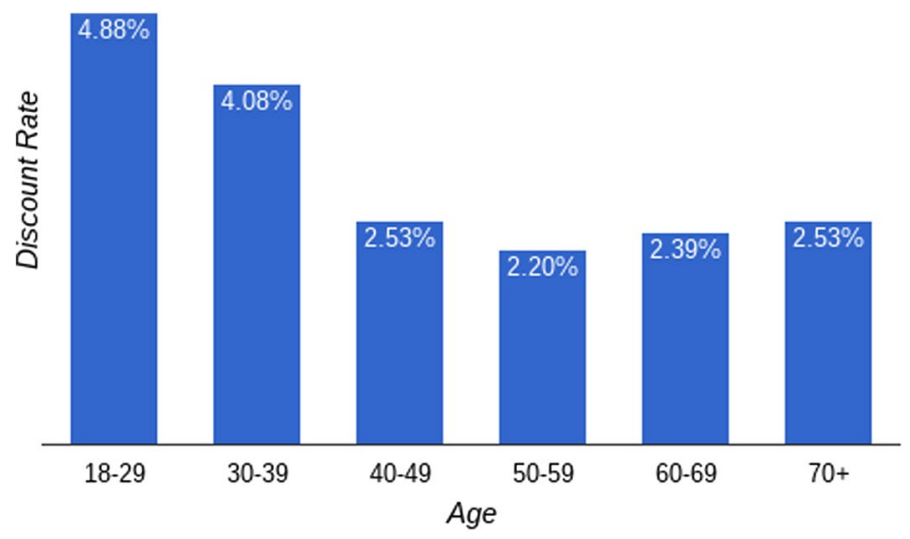

Fig. 6 Temporal discount rate by age group

\subsection{Estimation Strategy}

As explained above, three dependent variables were used in the study. These are measures of Evaluative, Hedonic and Expected Wellbeing. For each dependent variable four OLS regression analyses were employed. An OLS model was used since the data fulfilled its assumptions in each case (the results for these are available in "Appendix 4, ESM"). This is a more appropriate form of regression than an ordered probit or logit model because of the number of possible responses for the dependent variables. In the first of these three analyses, the dependent variable is included alongside only the discount rate variable. In the second, demographic information is also included. In the third, broader variables were added. In the fourth and final analysis the discount rate was then removed to see whether this removal significantly affects the model. The total number of the sample for which there was complete data was 1869 , since in some cases, the answer "don't know" was given to the questions addressing the dependent variables. These were removed from the analysis.

Multicollinearity tests were performed for all models using the Variance Inflation Factors test. None of the models were found to have troubling multicollinearity issues. With the known collinearity between the age and age squared variables acknowledged, the highest VIF score is 1.6 and as such is not cause for concern (full results in "Appendix 4, ESM").

Due to its exploratory nature, this study focuses on correlations between the studied variables rather than causation.

\section{Results}

\subsection{The Discount Rate and Evaluative Wellbeing}

Table 2 shows the results of the hierarchical regression performed to test the relationship between the discount rate and evaluative wellbeing.

With the discount rate as the only independent variable the model is significant and the discount rate is a significant negative predictor of evaluative wellbeing at the $0.1 \%$ level (Model 1). Each one percentage point increase in a person's aggregate discount rate predicts a 2.9 point reduction on the $1-10$ scale of evaluative wellbeing. 
Table 2 Discount rate and evaluative wellbeing, OLS results

\begin{tabular}{|c|c|c|c|}
\hline & \multicolumn{3}{|c|}{$\begin{array}{l}\text { Dependent variable: "How satisfied you are with your life these } \\
\text { days?" (1-10) }\end{array}$} \\
\hline & Model 1 & Model 2 & Model 3 \\
\hline Discount rate & $\begin{array}{l}-2.945^{* * *} \\
(1.128)\end{array}$ & $\begin{array}{l}-3.025 * * * \\
(1.024)\end{array}$ & $\begin{array}{c}-2.994 * * * \\
(0.940)\end{array}$ \\
\hline \multicolumn{4}{|l|}{ Socio-demographic controls } \\
\hline Women & & $\begin{array}{c}0.111 \\
(0.086)\end{array}$ & $\begin{array}{l}0.211^{* * * *} \\
(0.082)\end{array}$ \\
\hline Age & & $\begin{array}{l}-0.079 * * * \\
(0.020)\end{array}$ & $\begin{array}{c}-0.046^{* * *} \\
(0.018)\end{array}$ \\
\hline Age squared & & $\begin{array}{l}0.001 * * * \\
(0.000)\end{array}$ & $\begin{array}{l}0.001 * * * \\
(0.000)\end{array}$ \\
\hline Degree or above education & & $\begin{array}{c}-0.221 * * \\
(0.090)\end{array}$ & $\begin{array}{c}-0.193 * * \\
(0.083)\end{array}$ \\
\hline Household income (£pa) & & $\begin{array}{l}0.199 * * * \\
(0.024)\end{array}$ & $\begin{array}{l}0.090 * * * \\
(0.023)\end{array}$ \\
\hline Health (1-5 good-poor) & & $\begin{array}{l}-0.860 * * * \\
(0.050)\end{array}$ & $\begin{array}{c}-0.558 * * * \\
(0.049)\end{array}$ \\
\hline Unemployed & & $\begin{array}{r}-0.052 \\
(0.110)\end{array}$ & $\begin{array}{r}-0.159 \\
(0.101)\end{array}$ \\
\hline \multicolumn{4}{|l|}{ Other controls } \\
\hline Commute (enjoyment 1-10) & & & $\begin{array}{l}0.105 * * * \\
(0.017)\end{array}$ \\
\hline Hours of sleep & & & $\begin{array}{l}0.151 * * * \\
(0.033)\end{array}$ \\
\hline Income relative to friends & & & $\begin{array}{l}0.252^{* * * *} \\
(0.019)\end{array}$ \\
\hline Extraversion & & & $\begin{array}{l}0.074 * * * \\
(0.015)\end{array}$ \\
\hline Agreeableness & & & $\begin{array}{r}-0.019 \\
(0.019)\end{array}$ \\
\hline Conscientiousness & & & $\begin{array}{r}-0.028 \\
(0.019)\end{array}$ \\
\hline Neuroticism & & & $\begin{array}{c}-0.116^{* * * *} \\
(0.017)\end{array}$ \\
\hline Openness & & & $\begin{array}{c}-0.052 * * * \\
(0.019)\end{array}$ \\
\hline Constant & $\begin{array}{l}6.796^{* * * *} \\
(0.058)\end{array}$ & $\begin{array}{l}9.239 * * * \\
(0.469)\end{array}$ & $\begin{array}{l}5.486^{* * * *} \\
(0.526)\end{array}$ \\
\hline Observations & 1869 & 1869 & 1869 \\
\hline $\mathrm{F}$ & 6.87 & 66.83 & 65.82 \\
\hline Prob $>$ F & 0.009 & 0.000 & 0.000 \\
\hline $\mathrm{R}^{2}$ & 0.004 & 0.223 & 0.363 \\
\hline
\end{tabular}

Significant at $* 10 \%, * * 5 \%, * * * 1 \%$ 
Table 3 Discount rate and evaluative wellbeing, OLS results of alternative measures of discount rate

\begin{tabular}{lllll}
\hline & Coefficient & $\mathrm{t}$ & $p>\mathrm{t}$ & $\mathrm{R}^{2}$ \\
\hline$£ 10,000$ over 6 weeks & -0.0001337 & -2.75 & 0.006 & 0.3616 \\
$£ 10,000$ over 9 months & -0.0001401 & -3.01 & 0.003 & 0.3617 \\
$£ 10,000$ over 42 months & -0.0000726 & -2.14 & 0.033 & 0.3607 \\
$£ 100,000$ over 6 weeks & -0.0001386 & -3.06 & 0.002 & 0.3627 \\
$£ 100,000$ over 9 months & -0.0001418 & -3.12 & 0.002 & 0.3621 \\
$£ 100,000$ over 42 months & -0.0000693 & -1.97 & 0.049 & 0.3604 \\
Holiday & -0.0270779 & -3.07 & 0.002 & 0.3605 \\
\hline
\end{tabular}

Once demographic factors are added to the model, the discount rate's power as a predictor of wellbeing increases further (Model 2). The coefficient of the discount rate is increased in magnitude to 3.0 and its significance as a predictor of wellbeing is only exceeded by age, income and health. The $\mathrm{R}^{2}$ value for the model has risen to 0.223 .

In Model 3, when the broader set of variables are all included, the model's $\mathrm{R}^{2}$ value rises to 0.36 . The significance of the discount rate's contribution remains at the highest level of significance. Its coefficient remains around the point 3 mark at -2.99 . Additional Sobel-Goodman mediation tests were performed to quantify the extent of health and household income's mediation effects on this relationship. These found that health mediated $36 \%$ of the discount rate's effect on life satisfaction while household income accounted for $11 \%$ (full tables in "Appendix 4, ESM").

Age, age squared, household income and health are all also predictors at the $0.1 \%$ level.

A final, fourth model was performed in which the discount rate variable was removed from Model 3. These two models were then compared using an F test. The removal of the discount rate from Model 3 was found to result in a significant fall in the strength of the model $(\mathrm{F}(1,1852)=10.95, p<0.001)$. As a robustness check Model 3 above was also performed using an ordered probit regression with the same result-the discount rate was found to be significant at the $>99.9 \%$ level.

The full Tables for both of these Models are available in "Appendix 4, ESM".

\subsection{Alternative Discount Rate Variables and Evaluative Wellbeing}

The overall discount rate variable used above is based on 6 different measurements (as described in the methods section). Each of these 6 is a different discount rate calculation based on a varying reward amount and timescale. For the results below, model 3 from the main analysis was utilised with the overall discount rate variable replaced with the result of each of these 6 calculations in order to investigate how the impact of the discount rate varied by reward size and the timing of the reward. In addition to these analyses, the final regression analysis was performed using the alternative, non-financial discount rate measure based on rewards of days holiday. In each case the variable measures the size of a potential sacrifice, so a negative coefficient corresponds to a greater discount rate predicting lower life satisfaction. The full regression tables for each of the 7 rows below are available in "Appendix 4, ESM" (Table 3).

All of the individual conditions were found to be predictive of the discount rate, as a minimum, at the $95 \%$ level. The two weakest predictors are the longer term, 3 and a half year conditions. The 4 shorter term trade-offs are broadly indistinguishable in their 
predictive value, though the $t$ values are slightly higher in the $£ 100,000$ condition than for the $£ 10,000$ incentive.

Overall, prediction appears to be more powerful in shorter term conditions, and possibly at higher values of reward, though this latter difference is of a much smaller magnitude.

The non-financial variant in which people were asked how many days holiday they would concede today to receive a 10 day holiday bonus that is scheduled for next year, was found to be as predictive of evaluative wellbeing as in any other condition (99.9\%).

\subsection{Hedonic Wellbeing}

The same approach was used analyse hedonic wellbeing as employed with evaluative wellbeing. In Model 1, with the discount rate as the only independent variable, the model is not significant, nor is the discount rate a significant predictor of hedonic wellbeing.

Once demographic factors are added the model itself becomes significant and the discount rate's effect is significant at the $90 \%$ level (Model 2).

In the third model where the wider set of variables were included in the model, the discount rate was again a significant predictor at the $90 \%$ level with a coefficient of just below 1.8. This means that the relationship between the Discount rate and Hedonic Wellbeing is of a lower level of statistical significance and a less powerful predictor than for evaluative wellbeing with a 1 point increase in the discount rate predicting a fall of less than 2 points of the hedonic wellbeing scale (compared to an equivalent fall of 3 points on a 10 point scale for evaluative wellbeing). Mediation effects were tested for both health and income and were not found to be significant.

In this model, income is no longer significant, however, 'income in comparison to friends' is highly significant. Poor health, unemployment and age-squared all remain highly significant predictors of low levels of hedonic wellbeing (Table 4).

As for evaluative wellbeing, a final, fourth Model was applied in which the discount rate variable was removed from Model 3. The removal of the discount rate was found to result in a significant fall in the strength of the model, though not to the level of significance seen with evaluative wellbeing. $(\mathrm{F}(1,1852)=2.97, p<0.1)$. As a robustness check, a replication of Model 3 was performed with an ordered probit regression which found the discount rate to be significant at the $95 \%$ level. The full tables for both of these models are available in "Appendix 4, ESM".

\subsection{Alternative Discount Rate Variables and Hedonic Wellbeing}

The final regression analysis was performed with the alternative, non-financial discount rate variable and each of the 6 constituent trade-offs that comprise the above discount rate variable on their own. The key results are shown in Table 5 below and the full regression tables for each of the 7 rows below are available in "Appendix 4, ESM".

None of the financial variants were found to be significantly predictive of the discount rate in this model. However, the non-financial variant in which people were asked how many days holiday they would concede today to receive a 10 day holiday bonus that is scheduled for next year instead, was found to be a significant predictor of hedonic wellbeing (95\%). 
Table 4 Discount rate and hedonic wellbeing, OLS results

\begin{tabular}{|c|c|c|c|}
\hline & \multicolumn{3}{|c|}{$\begin{array}{l}\text { Dependent variable: "How happy do you feel right at this } \\
\text { moment?" (1-10) }\end{array}$} \\
\hline & Model 1 & Model 2 & Model 3 \\
\hline Discount rate & $\begin{array}{r}-1.600 \\
(1.145)\end{array}$ & $\begin{array}{r}-1.860^{*} \\
(1.104)\end{array}$ & $\begin{array}{r}-1.792^{*} \\
(1.040)\end{array}$ \\
\hline \multicolumn{4}{|l|}{ Socio-demographic controls } \\
\hline Women & & $\begin{array}{c}0.010 \\
(0.093)\end{array}$ & $\begin{array}{c}0.095 \\
(0.091)\end{array}$ \\
\hline Age & & $\begin{array}{l}-0.070^{* * *} \\
(0.021)\end{array}$ & $\begin{array}{r}-0.036^{*} \\
(0.020)\end{array}$ \\
\hline Age squared & & $\begin{array}{l}0.001 * * * \\
(0.000)\end{array}$ & $\begin{array}{l}0.000 * * \\
(0.000)\end{array}$ \\
\hline Degree or above & & $\begin{array}{l}-0.280 * * * \\
(0.097)\end{array}$ & $\begin{array}{c}-0.253 * * * \\
(0.091)\end{array}$ \\
\hline Household income (£pa, banded) & & $\begin{array}{l}0.134 * * * \\
(0.026)\end{array}$ & $\begin{array}{c}0.027 \\
(0.025)\end{array}$ \\
\hline Health (1-5 good-poor) & & $\begin{array}{l}-0.689 * * * \\
(0.054)\end{array}$ & $\begin{array}{c}-0.408 * * * \\
(0.054)\end{array}$ \\
\hline Unemployed & & $\begin{array}{r}-0.136 \\
(0.119)\end{array}$ & $\begin{array}{c}-0.226^{* *} \\
(0.111)\end{array}$ \\
\hline \multicolumn{4}{|l|}{ Other controls } \\
\hline Commute (enjoyment 1-10) & & & $\begin{array}{l}0.085^{* * * *} \\
(0.018)\end{array}$ \\
\hline Hours of sleep & & & $\begin{array}{l}0.165 * * * \\
(0.036)\end{array}$ \\
\hline Income relative to friends & & & $\begin{array}{l}0.250 * * * \\
(0.021)\end{array}$ \\
\hline Extraversion & & & $\begin{array}{l}0.066^{* * * *} \\
(0.017)\end{array}$ \\
\hline Agreeableness & & & $\begin{array}{r}-0.013 \\
(0.021)\end{array}$ \\
\hline Conscientiousness & & & $\begin{array}{r}-0.012 \\
(0.021)\end{array}$ \\
\hline Neuroticism & & & $\begin{array}{c}-0.096^{* * *} \\
(0.019)\end{array}$ \\
\hline Openness & & & $\begin{array}{c}-0.048 * * \\
(0.021)\end{array}$ \\
\hline Constant & $\begin{array}{l}6.602 * * * \\
(0.059)\end{array}$ & $\begin{array}{l}9.071 * * * \\
(0.505)\end{array}$ & $\begin{array}{l}5.486^{* * *} \\
(0.526)\end{array}$ \\
\hline Observations & 1869 & 1869 & 1869 \\
\hline $\mathrm{F}$ & 1.95 & 33.95 & 37.65 \\
\hline Prob $>F$ & 0.162 & 0.000 & 0.000 \\
\hline $\mathrm{R}^{2}$ & 0.001 & 0.127 & 0.245 \\
\hline
\end{tabular}

Significant at $* 10 \%, * * 5 \%, * * * 1 \%$ 
Table 5 Discount rate and hedonic wellbeing, OLS results of alternative measures of discount rate

\begin{tabular}{lllll}
\hline & Coefficient & $\mathrm{t}$ & $p>\mathrm{t}$ & $\mathrm{R}^{2}$ \\
\hline$£ 10,000$ over 6 weeks & -0.0000795 & -1.48 & 0.139 & 0.2451 \\
$£ 10,000$ over 9 months & -0.0000792 & -1.54 & 0.124 & 0.2445 \\
$£ 10,000$ over 42 months & -0.0000465 & -1.24 & 0.217 & 0.2436 \\
$£ 100,000$ over 6 weeks & -0.0000689 & -1.38 & 0.169 & 0.2449 \\
$£ 100,000$ over 9 months & -0.0000766 & -1.52 & 0.128 & 0.245 \\
$£ 100,000$ over 42 months & -0.0000525 & -1.35 & 0.177 & 0.2438 \\
Holiday & -0.0247307 & -2.54 & 0.011 & 0.244 \\
\hline
\end{tabular}

\subsection{Predicted Wellbeing}

The sample size for the analyses in Table 6 are slightly diminished from those for the previous two aspects of wellbeing. This is the result of a higher incidence of respondents selecting the response option 'don't know' in response to the predicted wellbeing question $(n=104)$. These respondents were excluded from the analyses.

In the model with no other accompanying dependent variables (Model 1) the discount rate is a significant (99\%) positive predictor of predicted wellbeing. The model itself was also found to be significant at the highest level. A one percentage point increase in the discount rate predicts a 4.3 point rise in predicted wellbeing on a scale of 0 to 10 (compared to a fall of 2.9 for evaluative wellbeing).

Once demographic factors are added into the model the discount rate remains a significant positive predictor (99\%) (Model 2). The model as a whole remains significant at the highest level, while a one percentage point increase in the discount rate now predicting a 2.7 point rise in predicted wellbeing on a scale of 0 to 10 . This fall in coefficient is likely to be the result of the significant correlation of the discount rate with age, income and health. As none of the correlations between these variables and the discount rate are particularly high, this is probably an accumulative effect of all these variables. All three variables are predictive of an increased likelihood of expecting to be happier in the future.

With the addition of the broader variables (Model 3) the discount rate remains highly predictive of predicted wellbeing. A one percentage point increase in the aggregate discount rate predicts a 2.6 point rise in expected wellbeing (compared to a fall of 3 for evaluative wellbeing and a fall of 1.8 for hedonic wellbeing). The model remains highly significant. As in the case of hedonic wellbeing, mediation effects were tested for both health and income, and were not found to be significant.

In this analysis, age-squared is no longer significant while age is highly significant (99\%). A decade increase in age corresponds with a half a point reduction in expected wellbeing. As for hedonic wellbeing, gross income is no longer significant as a predictor in this model, whereas income in comparison to friends is significant at the highest level.

As in the previous two studies a fourth Model was performed in which the discount rate variable was removed from Model 3. The removal of the discount rate was found to result in a significant fall in the strength of the model $(\mathrm{F}(1,1748)=9.01, p<0.01)$. Just as for evaluative and hedonic wellbeing, a replication of Model 3 was performed with an ordered probit regression as a robustness check. As in the OLS regression, this test showed the discount rate 
Table 6 Discount rate and evaluative wellbeing, OLS results

\begin{tabular}{|c|c|c|c|}
\hline & \multicolumn{3}{|c|}{$\begin{array}{l}\text { Dependent variable: "Do you expect to be happier or less } \\
\text { happy in } 2 \text { years time?" }(1-10)\end{array}$} \\
\hline & Model 1 & Model 2 & Model 3 \\
\hline Discount rate & $\begin{array}{l}4.317 * * * \\
(0.902)\end{array}$ & $\begin{array}{l}2.722 * * * \\
(0.890)\end{array}$ & $\begin{array}{l}2.635 * * * \\
(0.878)\end{array}$ \\
\hline \multicolumn{4}{|l|}{ Socio-demographic controls } \\
\hline Women & & $\begin{array}{l}0.171 * * \\
(0.075)\end{array}$ & $\begin{array}{l}0.150 * * \\
(0.076)\end{array}$ \\
\hline Age & & $\begin{array}{l}-0.053 * * * \\
(0.017)\end{array}$ & $\begin{array}{l}-0.048^{* * *} \\
(0.017)\end{array}$ \\
\hline Age squared & & $\begin{array}{l}0.000^{* *} \\
(0.000)\end{array}$ & $\begin{array}{c}0.000 \\
(0.000)\end{array}$ \\
\hline Degree or above & & $\begin{array}{r}-0.003 \\
(0.078)\end{array}$ & $\begin{array}{r}-0.021 \\
(0.077)\end{array}$ \\
\hline Household income (£pa, banded) & & $\begin{array}{l}0.043 * * \\
(0.021)\end{array}$ & $\begin{array}{c}0.013 \\
(0.022)\end{array}$ \\
\hline Health (1-5 good-poor) & & $\begin{array}{l}-0.326^{* * *} \\
(0.044)\end{array}$ & $\begin{array}{l}-0.222 * * * \\
(0.045)\end{array}$ \\
\hline Unemployed & & $\begin{array}{c}0.052 \\
(0.096)\end{array}$ & $\begin{array}{c}0.032 \\
(0.094)\end{array}$ \\
\hline \multicolumn{4}{|l|}{ Other controls } \\
\hline Commute (enjoyment $1-10$ ) & & & $\begin{array}{l}0.073 * * * \\
(0.016)\end{array}$ \\
\hline Hours of sleep & & & $\begin{array}{c}0.041 \\
(0.031)\end{array}$ \\
\hline Income relative to friends & & & $\begin{array}{l}0.063 * * * \\
(0.018)\end{array}$ \\
\hline Extraversion & & & $\begin{array}{l}0.045^{* * * *} \\
(0.014)\end{array}$ \\
\hline Agreeableness & & & $\begin{array}{c}-0.046^{* *} \\
(0.018)\end{array}$ \\
\hline Conscientiousness & & & $\begin{array}{r}-0.025 \\
(0.018)\end{array}$ \\
\hline Neuroticism & & & $\begin{array}{r}-0.014 \\
(0.016)\end{array}$ \\
\hline Openness & & & $\begin{array}{l}0.050 * * * \\
(0.018)\end{array}$ \\
\hline Constant & $\begin{array}{l}6.602 * * * \\
(0.059)\end{array}$ & $\begin{array}{l}8.883 * * * \\
(0.418)\end{array}$ & $\begin{array}{l}7.633 * * * \\
(0.501)\end{array}$ \\
\hline Observations & 1765 & 1765 & 1765 \\
\hline $\mathrm{F}$ & 22.89 & 22.72 & 17.86 \\
\hline Prob $>F$ & 0 & 0 & 0 \\
\hline $\mathrm{R}^{2}$ & 0.0128 & 0.0938 & 0.1405 \\
\hline
\end{tabular}

Significant at $* 10 \%, * * 5 \%, * * * 1 \%$ 
Table 7 Discount rate and hedonic wellbeing, OLS results of alternative measures of discount rate

\begin{tabular}{lllll}
\hline & Coefficient & $\mathrm{t}$ & $p>\mathrm{t}$ & $\mathrm{R}^{2}$ \\
\hline$£ 10,000$ over 6 weeks & 0.0000392 & 0.86 & 0.39 & 0.1362 \\
$£ 10,000$ over 9 months & 0.0001675 & 3.91 & 0 & 0.145 \\
$£ 10,000$ over 42 months & 0.0000795 & 2.52 & 0.012 & 0.1392 \\
$£ 100,000$ over 6 weeks & 0.0000392 & 0.94 & 0.346 & 0.1355 \\
$£ 100,000$ over 9 months & 0.0001087 & 2.69 & 0.007 & 0.1401 \\
$£ 100,000$ over 42 months & 0.0001009 & 3.16 & 0.002 & 0.1418 \\
Holiday & 0.0067598 & 0.82 & 0.414 & 0.1378 \\
\hline
\end{tabular}

to be significant at the $>99 \%$ level. The full Tables for both of these models are available in "Appendix 4, ESM".

\subsection{Alternative Discount Rate Variables and Predicted Wellbeing}

As with the other two independent variables, the final regression analysis was performed with the alternative, non-financial discount rate variable and each of the 6 constituent trade-offs that comprise the overall variable. The full regression tables for each of the 7 rows below are available in "Appendix 4, ESM" (Table 7).

There appears to be a clear effect of timescale on the effectiveness of the discount rate as a predictor of predicted wellbeing. The 6 week conditions are not found to be significant with either reward amount, whereas their $t$ values are much greater in the 9 and 42 month conditions. The holiday condition was not found to be significant.

\section{Discussion}

A lower discount rate appears to strongly predictive of evaluative wellbeing (hypothesis 1). It is a weaker predictor of hedonic wellbeing (hypothesis 2). Rather unexpectedly, a higher discount rate predicts higher predicted future wellbeing (contrary to hypothesis 3 ). This result - that those who discount heavily are less likely to be satisfied with their lives at present, but more likely to believe that things will improve-can be explained in several ways.

The first possibility is that people who discount heavily are worse at predicting their future conditions. If they are less likely to be satisfied with their life, yet more likely to believe things will improve, it would seem logical to conclude that they are either less aware of their current conditions, or-far more likely - that they are less able to predict their future conditions. Or, both. Combined with the finding that a high discount rate predicts lower levels of wellbeing, it appears to be the case that lower discounters are more accurate at gauging their own future wellbeing. Currently, evidence of increasing happiness over the life cycle is thin on the ground. A potentially relevant finding is one reported by Lang et al. (2013), who found that lower expected life satisfaction acted as a guard against negative health outcomes-those who anticipate a darker future may possibly obtained a benefit to wellbeing in doing so, as they will avoid disappointment. It seems possible that there is a possible common thread between these three findings; 
that realistic expectations may act as a guard against future dissatisfaction and hence, lower wellbeing. Those with smaller discounts are those who more accurately predict the future, hence their less exaggerated expectations of happiness.

Interestingly, one of the explanations offered for the U-shape in happiness with increasing age is that it is reflective of unrealistic expectations in youth, tempered by reality in middle age, before reconciliation with the discrepancy of expectations and reality in older age (Blanchflower and Oswald 2008). This is something that may well be mirrored in high discounters when their own expectations are not met. The disparity in expectations is likely at least partially a result of the same differential in detection systems already shown to exist between high and low discounters (de Wit et al. 2007; Dohmen et al. 2007; Funder and Block 1989; Shamosh and Gray 2007). Large temporal discounts appear not only to predict inefficient decisions, but are also linked to unhappiness. The former effect was sufficient to make the discount rate worthy of study, the latter effect makes this and future studies essential.

This study also implies strongly that temporal discounting is not an expression of pessimism. If anything, these data suggest that heavy discounters are more optimistic (and/ or unrealistic) about their future conditions. It also suggests that someone with a high discount rate isn't likely to be less happy because they're pessimistic about the future, quite the reverse - they expect to be happier in future than their low discounting peer.

Furthermore, the results of this study lend evidence to the idea that the discount rate is a stable and distinct trait. The counter-intuitive effects of the discount rate may be indicative of its distinctiveness as an individual characteristic. The construct appears to be resistant to the expectations that it itself produces, implying stability. The correlational data also suggests that it sits between and outside of the established "Big 5" personality traits. These results suggest that Odum's (2011) conclusion that the discount rate is a distinct and enduring trait may be correct.

Another interesting contrast in these data is that between the discount rate's relationships with evaluative and hedonic wellbeing. As tentatively predicted in the Introduction, the association with the former is far stronger. There is an intuitive feel to this result, in that hedonic wellbeing is defined as being more of a 'in the moment' construct. The impacts of the discount rate may be less obvious to this element of wellbeing as, unlike evaluative wellbeing, this kind of momentary happiness doesn't involve the assessment of life as a whole and the evaluation of the quality of our decisions. This differentiation in the results supports Layard's (2011) and, indeed, Aristotle's (1925) work on the different "quality" of various types of happiness.

A final aspect of the study worth highlighting is the importance of health and wealth in this area of study. The bulk of previous research on the negative impacts of a heavy discount rate have focused around poor decisions about our health and finances. These effects are well established (Story et al. 2014) and were part of the initial hypotheses about the impact of the discount rate on life satisfaction. Measures of both were included in the regression models, yet had little impact on the significance of the discount rate's predictive power compared to previous stepped models in which they were not included. Furthermore, mediation tests suggest that though they do perform such a role in the case of evaluative wellbeing (as expected and predicted), the effect is modest and in the main the relationships found in this study independent of these factors. 


\subsection{Limitations}

This study is subject to the same shortcomings as all that seeks to capture subjective variables such as wellbeing using quantitative approaches. That said, the study used measures that have commonly been used in research in this field and that have demonstrated have high levels of consistency between studies, over time and with external proxies (Layard 2011).

An additional variable to consider in future research is that of religiosity. Results examining its association with happiness and wellbeing are mixed, with plenty of studies supporting both the presence and absence of an association between religious beliefs and increased wellbeing (Francis et al. 2000; Lewis et al. 1997; Sahraian et al. 2013; Unterrainer et al. 2014). However, as Carter et al. (2012) have provided evidence that religious people may discount the future less as a whole, this is a possible relationship worth examining in future regression models.

Increasing the sample size of this study still further is another potential area for improvement. Though a sample of 2000 people structured to be demographically nationally representative of the UK allowed for strong statistical conclusions, larger national surveys have even greater potential to improve understanding. This is particularly true for the study of the changing nature of discount rate relationships over the life cycle. This study was ill-equipped to answer this question, since once divided into generations the sample sizes were not always able to support rigorous regression analysis. This changing effect should be the subject of its own dedicated study in future, with a larger sample base to work from. A longitudinal study would also be a natural progression from here, so as to measure how these relationships change within individuals and groups over time.

\subsection{Future Research}

The results provide a useful platform for more research into the association between wellbeing and the discount rate. Despite being complex structures to summarise as a whole, elements of each of these constructs can be measured and considered together. It is reassuring that the shape of the data collected in this study relating to the discount rate is similar to that previously established by authors such as Odum (2011). Future research would benefit from measuring the discount rate in creative ways other than purely in financial terms where possible. This study has demonstrated that the effects of the discount rate on various decisions (for example, financial and health-related decisions) and it would be helpful to understand better these differential effects on decision making in other areas in future.

Future studies may seek to focus more explicitly on the extent to which the discount rate, health and wealth interact and mediate one another when it comes to wellbeing. All three have predictive power in this arena and mediation tests show that a portion of this influence is shared, but it was outside of the remit of this study to quantify this crossover fully. Other research could profitably focus more heavily on the effects of the age variable, since as discussed in the Introduction, it seems intuitive that any such effects would accumulate over the lifecycle.

Another beneficial strand of research would be the investigation of the practical implications of the relationship between the discount rate and wellbeing. Since the discount rate has now been shown to be related to health, finance and life satisfaction, attention should now turn to the possibly causal nature of these relationships. One relatively simple way of doing this would be to attempt to manipulate the individual discount rate and compare the 
results on wellbeing to a matched control sample. Should this manipulation prove to be effective, it may be possible to develop simple interventions in which people could assess their own rates, then apply techniques along the lines of sophistication and pre-commitment that allow people to account for their own individual discount rate and its possible implications in their decision-making.

Because of the temporal effects of the discount rate, attempts to assess it will always benefit from a great number of measurements on a varying timescale. The results of this study showed differential effects on different aspects of wellbeing. For example, the relationship between the discount rate and predicted wellbeing appeared to be driven most strongly by its longer term iterations - those over 9 months and 3 and a half years. It is hard to say whether the relationship would be even stronger if the variable was comprised of even longer term measurements, but, were these and shorter term measurements to be included in a future study, this would allow for inspection of the linearity of this relationship across time and how this varies for different dependent variables. The results of this study suggest that these temporal effects are reversed for evaluative wellbeing (Table 3), with the shorter timescale producing a stronger relationship. In contrast, the results for hedonic wellbeing (Table 5) show little effect of the timescales to which the discount rate was applied.

In conclusion, the results of this study demonstrate that further research into the role of the discount rate in wellbeing has the potential to be provide a rich stream of new understanding in human behaviour, particularly with regards to wellbeing.

\section{Compliance with Ethical Standards}

Conflict of interest The author declares that he has no conflicts of interest.

Open Access This article is distributed under the terms of the Creative Commons Attribution 4.0 International License (http://creativecommons.org/licenses/by/4.0/), which permits unrestricted use, distribution, and reproduction in any medium, provided you give appropriate credit to the original author(s) and the source, provide a link to the Creative Commons license, and indicate if changes were made.

\section{References}

Aristotle. (1925). The Nicomachean ethics. New York, NY: Oxford University Press. (D. Ross, Trans. L. Brown, Ed.).

Bickel, W. K., Yi, R., Landes, R. D., Hill, P. F., \& Baxter, C. (2011). Remember the future: Working memory training decreases delay discounting among stimulant addicts. Biological Psychiatry, 69, 260-265. https://doi.org/10.1016/j.biopsych.2010.08.017.

Blanchflower, D., \& Oswald, A. (2008). Is Well-being U-shaped over the life cycle? Social Science and Medicine, 66(6), 1733-1749.

Boyce, C. J., \& Wood, A. M. (2010). "Money or mental health: The cost of alleviating psychological distress with monetary compensation versus psychological therapy. Health Economics Policy and Law, 5, 509-516.

Boyle, P. A., Yu, L., Gamble, K. J., \& Bennett, D. A. (2013). Temporal discounting is associated with an increased risk of mortality among community-based older persons without dementia. PLOS ONE, 8(6), e67376. https://doi.org/10.1371/journal.pone.0067376.

Brewer, M., Goodman, A., \& Leicester, A. (2006). Household spending in Britain: What can it teach us about poverty?. Bristol: Policy Press.

Carter, E. C., McCullough, M. E., Kim-Spoon, J., Corrales, C., \& Blake, A. (2012). Religious people discount the future less. Evolution and Human Behavior, 33(3), 224-231. 
Chabris, C. F., Laibson, D. I., \& Schuldt, J. P. (2008). Intertemporal choice. In S. N. Durlauf \& L. E. Blume (Eds.), The new Palgrave dictionary of economics (2nd ed.). London: Palgrave Macmillan.

Chapman, G. B., \& Elstein, A. S. (1995). Valuing the future: Temporal discounting of health and money. Medical Decision Making, 15, 373-386.

De Wit, H., Flory, J. D., Acheson, A., McCloskey, M., \& Manuck, S. B. (2007). IQ and nonplanning impulsivity are independently associated with delay discounting in middle-aged adults. Personality and Individual Differences, 42, 111-121. https://doi.org/10.1016/j.paid.2006.06.026.

DellaVigna, S., \& Malmendier, U. (2006). Paying not to go to the gym. American Economic Review, 96(3), 694-719.

Dohmen, T., Falk, A., Huffman, D., \& Sunde, U. (2007). Are risk aversion and impatience related to cognitive ability? IZA Discussion Paper 2735.

Dolan, P., Peasgood, T., \& White, M. (2008). Do we really know what makes us happy? A review of the economic literature on the factors associated with subjective wellbeing. Journal of Economic Psychology, 29, 94-122.

Dolan, P., \& White, M. P. (2007). How can measures of subjective well-being be used to inform public policy? Perspectives on Psychological Science, 2(1), 71-85.

Easterlin, R. A., \& Angelescu, L. (2012). Modern economic growth and quality of life: Cross-sectional and time series evidence. In K. Land, A. Michalos \& M. Sirgy (Eds.), Handbook of social indicators and quality of life research. Dordrecht: Springer.

Ersner-Hershfield, H. M., Garton, T., Ballard, K., Samanez-Larkin, G. R., \& Knutson, B. (2009). Don't stop thinking about tomorrow: Individual differences in future self-continuity account for saving. Judgment and Decision Making, 4(4), 280-286.

Ferrer-i-Carbonell, A., \& Gowdy, J. (2005). Environmental awareness and happiness. Rensselaer Polytechnic Institute, Department of Economics, Rensselaer Working Papers in Economics.

Francis, L. J., Jones, S. H., \& Wilcox, C. (2000). Religiosity and happiness: During adolescence, young adulthood, and later life. Journal of Psychology and Christianity, 19(3), 245-257.

Frijters, P., Greenwell, H., Haisken-DeNew, J. P., \& Shields, M. A. (2009). How well do individuals predict their future life satisfaction? Evidence from panel data following a nationwide exogenous shock. Canadian Journal of Economics, 42(4), 1326-1346.

Funder, D. C., \& Block, J. (1989). The role of ego-control, ego-resiliency, and IQ in delay of gratification in adolescence. Journal of Personality and Social Psychology, 57(6), 1041-1050.

Gard, D. E., Gard, M. G., Kring, A. M., \& John, O. P. (2006). Anticipatory and consummatory components of the experience of pleasure: A scale development study. Journal of Research in Personality, 40(6), 1086-1102.

Grant, S., Langan-Fox, J., \& Anglim, J. (2009). The big five traits as predictors of subjective and psychological well-being. Psychological Reports, 105(1), 205-231.

Green, L., Myerson, J., Lichtman, D., Rosen, S., \& Fry, A. (1996). Temporal discounting in choice between delayed rewards: The role of age and income. Psychology and Aging, 11, 79-84. https://doi. org/10.1037/0882-7974.11.1.79.

Gubler, T., \& Pierce, L. (2014). Healthy, wealthy, and wise: Retirement planning predicts employee health improvements. Psychological Science, 25, 1822-1830.

Harrison, G. W., Lau, M. I., \& Rutstrom, E. E. (2010). Individual discount rates and smoking: Evidence from a field experiment in Denmark. Journal of Health Economics, 29(5), 708-717.

Helliwell, J., Layard, R., \& Sachs, J. (2016). World happiness report. New York: The Earth Institute, Columbia University.

Joshi, P., \& Fast, N. (2013). Power and reduced temporal discounting. Psychological Science, 24(4), 432-438.

Lang, F. R., Weiss, D., Gerstorf, D., \& Wagner, G. G. (2013). Forecasting life satisfaction across adulthood: Benefits of seeing a dark future? Psychology and Aging, 28(1), 249.

Layard, R. (2011). Happiness: Lessons from a new science. London: Penguin.

Lewis, C. A., Lanigan, C., Joseph, S., \& De Fockert, J. (1997). Religiosity and happiness: No evidence for an association among undergraduates. Personality and Individual Differences, 22(1), 119-121.

Loewenstein, G. (1987). Anticipation and the valuation of delayed consumption. The Economic Journal, 97(387), 666-684.

Manning, J., Hedden, T., Wickens, N., Whitfield-Gabrieli, S., Prelec, D., \& Gabrieli, J. D. (2014). Personality influences temporal discounting preferences: Behavioral and brain evidence. NeuroImage, 98 , 42-49.

Meier, S., \& Stutzer, A. (2007). Is volunteering rewarding in itself? Economica, 75(297), 39-59.

Mischel, W., \& Metzner, R. (1962). Preference for delayed reward as a function of age, intelligence, and length of delay interval. Journal of Abnormal and Social Psychology, 64, 425-431. 
O’Donoghue, T., \& Rabin, M. (1999). Doing it now or later. American Economic Review, 89(1), $103-124$.

Odum, A. L. (2011). Delay discounting: Trait variable. Behavioural Processes, 87, 1-9.

Reuben, E., Sapienza, P., \& Zingales, L. (2007). Procrastination and impatience (No. w13713). National Bureau of Economic Research.

Röcke, C., \& Lachman, M. E. (2008). Perceived trajectories of life satisfaction across past, present, and future: Profiles and correlates of subjective change in young, middle-aged, and older adults. Psychology and Ageing, 23(4), 833.

Sahraian, A., Gholami, A., Javadpour, A., \& Omidvar, B. (2013). Association between religiosity and happiness among a group of Muslim undergraduate students. Journal of Religion and Health, 52(2), $450-453$.

Shamosh, N. A., \& Gray, J. R. (2007). Delay discounting and intelligence: A meta-analysis. Intelligence. https://doi.org/10.1016/j.intell.2007.09.004.

Stiglitz, J. E., Sen, A., \& Fitoussi, J. P. (2009). Report of the commission on the measurement of economic performance et social progress, CMEPSP, September, 14, 2009. http://www.stiglitz-sen-fitoussi.fr/en/ documents.htm. Accessed on May 6, 2015.

Story, G. W., Vlaev, I., Seymour, B., Darzi, A., \& Dolan, R. J. (2014). Does temporal discounting explain unhealthy behavior? A systematic review and reinforcement learning perspective. Frontiers in Behavioral Neuroscience. https://doi.org/10.3389/fnbeh.2014.00076.

Stutzer, A., \& Frey, B. S. (2010). Recent advances in the economics of individual subjective well-being. Social Research, 77, 679-714.

Unterrainer, H. F., Lewis, A. J., \& Fink, A. (2014). Religious/spiritual well-being, personality and mental health: A review of results and conceptual issues. Journal of Religion and Health, 53(2), 382-392.

Warner, J. T., \& Pleeter, S. (2001). The personal discount rate: Evidence from military downsizing programs. American Economic Review, 91(1), 33-53.

World Values Survey Association. (2005). World values survey. Wave, 5, 2005-2008.

Publisher's Note Springer Nature remains neutral with regard to jurisdictional claims in published maps and institutional affiliations. 